\title{
Genome-Wide Association Studies of Estimated Fatty Acid Desaturase Activity in Serum and Adipose Tissue in Elderly Individuals: Associations with Insulin Sensitivity
}

\author{
Matti Marklund ${ }^{1,2, *(D)}$, Andrew P. Morris ${ }^{3}$, Anubha Mahajan ${ }^{4}$, Erik Ingelsson 5,6,7,8, \\ Cecilia M. Lindgren ${ }^{4,9}$, Lars Lind ${ }^{10}$ and Ulf Risérus ${ }^{2}$ \\ 1 The George Institute for Global Health, University of New South Wales, Sydney, NSW 2042, Australia \\ 2 Department of Public Health and Caring Sciences, Clinical Nutrition and Metabolism, Uppsala University, \\ 75122 Uppsala, Sweden; ulf.riserus@pubcare.uu.se \\ 3 Department of Biostatistics, University of Liverpool, Liverpool L69 3GL, UK; a.p.morris@liverpool.ac.uk \\ 4 The Wellcome Trust Centre for Human Genetics, Oxford OX3 7BN, UK; anubha@well.ox.ac.uk (A.M.); \\ celi@broadinstitute.org (C.M.L.) \\ 5 Department of Medicine, Division of Cardiovascular Medicine, Stanford University School of Medicine, \\ Stanford, CA 94305, USA; eriking@stanford.edu \\ 6 Stanford Cardiovascular Institute, Stanford University, Stanford, CA 94305, USA \\ Stanford Diabetes Research Center, Stanford University, Stanford, CA 94305, USA \\ 8 Department of Medical Sciences, Molecular Epidemiology, Uppsala University, 75185 Uppsala, Sweden \\ 9 Li Ka Shing Centre for Health Information and Discovery, The Big Data Institute, University of Oxford, \\ Oxford OX3 7LF, UK \\ 10 Department of Medical Sciences, Cardiovascular Epidemiology, Uppsala University, \\ 75185 Uppsala, Sweden; lars.lind@medsci.uu.se \\ * Correspondence: mmarklund@georgeinstitute.org.au; Tel.: +1-202-718-3443
}

Received: 16 October 2018; Accepted: 14 November 2018; Published: 17 November 2018

\begin{abstract}
Fatty acid desaturases (FADS) catalyze the formation of unsaturated fatty acids and have been related to insulin sensitivity (IS). FADS activities differ between tissues and are influenced by genetic factors that may impact the link to IS. Genome-wide association studies of $\delta$-5-desaturase (D5D), $\delta$-6-desaturase (D6D) and stearoyl-CoA desaturase-1 (SCD) activities (estimated by product-to-precursor ratios of fatty acids analyzed by gas chromatography) in serum cholesterol esters $(n=1453)$ and adipose tissue $(n=783$, all men) were performed in two Swedish population-based cohorts. Genome-wide significant associated loci were evaluated for associations with IS measured with a hyperinsulinemic euglycemic clamp $(n=554)$. Variants at the FADS1 were strongly associated with D5D in both cholesterol esters $\left(p=1.9 \times 10^{-70}\right)$ and adipose tissue $\left(p=1.1 \times 10^{-27}\right)$. Variants in three further loci were associated with D6D in cholesterol esters (FADS2, $p=3.0 \times 10^{-67} ; P D X D C I, p=4.8 \times 10^{-8}$; and near MC4R, $p=3.7 \times 10^{-8}$ ) but no associations with $\mathrm{D} 6 \mathrm{D}$ in adipose tissue attained genome-wide significance. One locus was associated with SCD in adipose tissue ( $P K D L 1, p=2.2 \times 10^{-19}$ ). Genetic variants near MC4R were associated with IS $\left(p=3.8 \times 10^{-3}\right)$. The FADS cluster was the main genetic determinant of estimated FADS activity. However, fatty acid (FA) ratios in adipose tissue and cholesterol esters represent FADS activities in separate tissues and are thus influenced by different genetic factors with potential varying effects on IS.
\end{abstract}

Keywords: fatty acid; desaturase; Genome-wide association study (GWAS); Insulin sensitivity; adipose tissue; cholesterol ester 


\section{Introduction}

Fatty acid desaturases (FADS) catalyze the formation of mono- and polyunsaturated fatty acid and thus influence the fatty acid (FA) composition of the blood stream and in adipose tissue (AT). The major human FADS include $\delta$-5-desaturase (D5D), $\delta$-6-desaturase (D6D) and $\delta$-9-desaturase or stearoyl-CoA desaturase-1 (SCD). While SCD synthesizes monounsaturated FA from saturated FA, D5D and D6D catalyze the formation of polyunsaturated FA. Since in vivo measurement of enzyme activity can be challenging, ratios of substrate and product concentrations are commonly used to estimate activities of SCD, D6D and D5D [1].

Both circulating fatty acid composition and estimated FADS activities have previously been associated with insulin sensitivity (IS) and incidence of type 2 diabetes (T2D), although the mechanisms underlying these relationships have not been fully determined [2]. It has been suggested that the effects of FADS on IS are mediated by alterations in FA compositions. This could lead to effects on cell membranes (influencing insulin receptor binding and affinity, translocation of glucose transporters and intercellular signaling) and altered levels of polyunsaturated fatty acids (PUFA) which function as ligands for a variety of transcription factors [3]. In addition, polymorphisms in the genes encoding for FADS have been was associated with fasting glucose levels and estimated $\beta$-cell function in a large-scale meta-analysis of genome-wide association studies (GWAS) [4].

Genome-wide associations of FADS activity estimated in the circulation have been reported previously and demonstrated that not only variants in desaturase encoding genes are associated with estimated FADS activity [5,6]. However, no prior GWAS have reported associations between genotype and activities of SCD, D5D, or D6D estimated in AT. Furthermore, previous studies investigating relationships between $F A D S$ polymorphisms and IS have relied on indirect measurements (e.g., fasting glucose and insulin) instead of gold standard methodology, such as the hyperinsulinemic euglycemic clamp.

The aim of the present study was to perform GWAS of FA metabolizing enzymes in AT and serum cholesterol esters (CE) in participants of the Uppsala Longitudinal Study of Adult Men (ULSAM) and the Prospective Investigation of the Vasculature in Uppsala Seniors (PIVUS). Subsequently, analyses were performed to investigate relationships between desaturase-associated genetic variants and cardiometabolic risk factors, including IS assessed by hyperinsulinemic euglycemic clamp.

\section{Materials and Methods}

\subsection{Study Samples}

Details about The Uppsala Longitudinal Study of Adult Men (ULSAM) are available in previous publications [7] and online at http:/ /www.pubcare.uu.se/ulsam/. In brief, at the first collection time-point, all 50-year-old men living in Uppsala County, Sweden, 1970-74, were invited. The present study includes individuals at the re-examination undertaken from August 1991 to May 1995 at the approximate age of 71 years, where 1221 out of 1681 invited individuals participated (73\% of those still alive and living in Uppsala). For the present study, we excluded individuals with missing microarray genotyping data $(n=5)$, failing sample quality control $(\mathrm{QC})(n=37)$, or missing all estimates of FADS activity ( $n=615$, cholesterol esters; $n=396$, adipose tissue).

A detailed study description of The Prospective Investigation of the Vasculature in Uppsala Seniors (PIVUS) has been published previously [8] and additional information can be found at http: / / www.medsci.uu.se/pivus/pivus.htm. In brief, all 70-year-old individuals living in Uppsala County, Sweden, between April 2001 and June 2004 were eligible for the study, out of which 2025 randomly selected subjects were invited. In total, 1016 subjects ( $50 \%$ women) participated and were examined within one month of their 70th birthday to standardize for age. For the present study, we excluded individuals with missing microarray genotyping data $(n=34)$, failing sample QC $(n=33)$, or missing all outcome measurements $(n=60)$. 
Both the ULSAM and PIVUS studies were approved by the ethics committee of Uppsala University and all participants provided written informed consent.

\subsection{Assessments of Fatty Acid Composition and Enzyme Activities}

Procedures for measurements of fatty acid composition in ULSAM and PIVUS have previously been described in detail $[9,10]$. Briefly, FA were measured in CE from blood samples drawn after an overnight fast, during which both medication and smoking were disallowed. A hexane-isopropanol solution was used to extract serum, from which cholesterol esters were separated by thin-layer chromatography followed by inter-esterification with acidic methanol. Free cholesterol was removed by aluminum oxide to avoid contamination of the column. The relative proportion of methylated FA was determined by gas chromatography (25-m NB-351 silica capillary column) with a coefficient of variation $<5.0 \%$. In addition, FA in subcutaneous AT were analyzed in ULSAM as previously described [10]. An estimate of enzyme activity was calculated as the product-to-substrate ratio; 20:4n-6/20:3n-6 for D5D, 18:3n-6/18:2n-6 for D6D and 16:1/16:0 for SCD.

\subsection{Assessments of Cardiometabolic Risk Factors}

Body mass index (BMI) was calculated as the ratio of body weight (in $\mathrm{kg}$ ) to height (in $\mathrm{m}$ ) squared. Concentrations of cholesterol and triglycerides were measured in serum and in isolated lipoprotein fractions by enzymatic techniques utilizing Instrumentation Laboratories (IL) Test Cholesterol Trinders's Method and IL Test enzymatic-colorimetric method for use in a monarch apparatus (Instrumentation Laboratories, Lexington, MA, USA). High-density lipoprotein (HDL) particles were separated by precipitation with magnesium chloride/phosphotungstate. IS was directly measured in the ULSAM cohort using the hyperinsulinemic euglycemic clamp, as previously described [11]. In addition, indices of insulin resistance (HOMA-IR) were assessed in both ULSAM and PIVUS as calculated using fasting concentrations of plasma glucose and insulin.

\subsection{Preparation of Genotype Data}

Genotyping was performed using the Illumina OmniExpress and Illumina Metabochip in PIVUS and Illumina Omni2.5M and Illumina Metabochip in ULSAM. General sample exclusion criteria included: (1) genotype call rate <95\%; (2) heterozygosity $>3$ SD from mean; (3) gender discordance; (4) duplicated samples; (5) identity-by-descent match; and (6) ethnic outliers. General single nucleotide polymorphism (SNP) exclusion criteria of genotyped data before imputation included: (1) monomorphic SNPs; (2) Hardy-Weinberg equilibrium (HWE) $p$-value $<1 \times 10^{-6}$; (3) genotype call rate $<99 \%$ (SNPs with minor allele frequency (MAF) $<5 \%$ ) or $<95 \%$ (SNPs with MAF $\geq 5 \%$ ); (4) MAF $<1 \%$. In ULSAM, for Omni2.5, further SNP exclusions were made if a SNP had large position disagreements, did not map in the genome, mapped more than once in the genome or had bad probe assays.

In PIVUS, 949 out of 982 samples passed QC for the OmniExpress; and Metabochip with the exclusions listed in Table S1. The genotyped data in PIVUS used in the present study consisted of 738,879 SNPs after QC. In ULSAM, 1179 out of 1216 samples passed QC for the Omni2.5 and Metabochip, with the exclusions listed in Table S1. The genotyped data in ULSAM consisted of $1,621,833$ SNPs after QC. Imputation was performed for the quality-controlled genotype data of each cohort with IMPUTE v.2.2.2 using haplotypes from the 1000 Genomes, March 2012 release (multi-ethnic panel on NCBI build 37 (b37)). Population substructures in the genotype data were captured using multidimensional scaling (MDS) of a genetic relationship matrix (genome file) constructed on the basis of linkage disequilibrium (LD)-pruned SNPs in PLINK 1.07 [12].

\subsection{Statistical Analysis}

Estimated enzyme activity levels were normalized using Blom's inverse normal transformation. Regression analyses of genetic variants and estimated desaturase activities were adjusted for the first 
two principal components of the MDS analysis. All regression analyses of the autosomes in ULSAM and PIVUS were performed separately in each study and then combined in sample size-weighted Z-score meta-analysis assuming fixed effects in the software METAL. [13] The same settings were used in the analysis of the X-chromosome as for the autosomes, with the exception that the analyses in PIVUS were stratified on gender before combining the results in the meta-analysis.

To identify single common variants associated with the estimated enzyme activity in CE, a genome-wide association analysis was performed using the score-based test in SNPTEST 2.4.1. (manufacturer, city, country) [14] Common variants (MAF $\geq 5 \%$ ) available in both studies and with an information quality metric $\geq 0.4$ were included in the analyses. A $p$-value $<5 \times 10^{-8}$ was considered to be genome-wide significant in these analyses. Further, to identify independent variants in each locus associated with enzyme activity levels, a forward selection conditional analysis was performed, where independent signals were considered down to a $p$-value of $\sim 1 \times 10^{-5}$. In addition, genome-wide association analyses of the estimated enzyme activity in AT were performed in ULSAM only.

A lookup was performed for the significant SNPs in the single variant analyses using literature and publicly available databases including RegulomeDB version 1.1 (http:/ / www.regulomedb.org /) [15], GTEx (http:/ / www.gtexportal.org/home/) [16], Metabolomics GWAS server (http:/ / mips.helmholtzmuenchen.de/proj/GWAS/gwas/) [5,6] and PhenoScanner (http:/ /www.phenoscanner.medschl.cam. ac.uk/phenoscanner) [17].

Associations of identified variants with cardiometabolic risk factors including triglycerides, HDL-C, BMI and HOMA-IR were assessed by linear regression in ULSAM and PIVUS separately and subsequently meta-analyzed using sample size-weighted fixed effects models. Similarly, associations between the same variants and $M$-value determined by hyperinsulinemic euglycemic clamp were assessed in ULSAM using linear regression models. For these associations between desaturase-associated loci and cardiometabolic risk factors, false discovery rate was used to correct for multiple testing [18].

\section{Results}

The clinical characteristics of individuals with available genotype and cholesterol ester fatty acid data in ULSAM $(n=564)$ and PIVUS $(n=889)$ are shown in Table 1 . In addition, a number of men $(n=783)$ in ULSAM also had data available on genotype and desaturase activity assessed in adipose tissue. The correlation between the estimated enzyme activity in CE and AT was low to moderate for $\operatorname{D5D}(r=0.36, p<0.0001), \operatorname{D6D}(r=0.10, p=0.098)$ and SCD $(r=0.40, p<0.0001)$.

Table 1. Clinical characteristics of individuals in ULSAM and PIVUS with genotype data and estimated desaturase activity in cholesterol esters. ${ }^{1}$

\begin{tabular}{ccc}
\hline & ULSAM $(\boldsymbol{n}=\mathbf{5 6 4})$ & PIVUS $(\boldsymbol{n}=\mathbf{8 8 9})$ \\
\hline Age & $71.3(0.4)$ & $70.2(0.2)$ \\
Women $(\%)$ & 0 & 49 \\
BMI $\left(\mathrm{kg} / \mathrm{m}^{2}\right)$ & $26.3(3.4)$ & $27.0(4.4)$ \\
Antihypertensive treatment $(\%)$ & 37 & 31 \\
Total cholesterol (mmol/L) & $5.8(1.0)$ & $5.4(1.0)$ \\
HDL cholesterol (mmol/L) & $1.3(0.3)$ & $1.5(0.4)$ \\
Triglycerides (mmol/L) & $1.5(0.8)$ & $1.3(0.6)$ \\
Lipid lowering treatment $(\%)$ & 9.4 & 15.9 \\
Fasting plasma glucose (mmol/L) & $5.8(1.5)$ & $6.0(1.8)$ \\
Glucose disposal, M (mg/kg/min) & $5.2(2.1)$ & $\mathrm{N} / \mathrm{A}$ \\
Diabetes treatment (\%) & 6.5 & 6.5 \\
Never smokers (\%) & 40 & 48 \\
Previous smokers (\%) & 40 & 41 \\
Current smokers (\%) & 20 & 11 \\
\hline
\end{tabular}

Values are mean (SD) or percentage. ${ }^{1}$ PIVUS, Prospective Investigation of Uppsala Seniors; ULSAM, Uppsala Longitudinal Study of Adult Men; HDL, high-density lipoprotein; BMI, body mass index; M, in vivo insulin-mediated glucose disposal. 


\subsection{GWAS of Desaturase Activity}

Quantile-quantile plots of $p$-values from the single variant association test of the enzyme activities showed no systematic deviation from the null (data not shown). Variation in one locus (fatty acid desaturase 1, FADS1) was associated with D5D and variants in or near three loci were associated with D6D (fatty acid desaturase 2, FADS2; pyridoxal-dependent decarboxylase domain containing 1, PDXDC1/N-terminal asparagine amidase, NTAN1; and near melanocortin 4 receptor, MC4R) (Figures S1 and S2). The significant lead variant for CE-D5D was also significant when analyzed in AT (Figure 1), unlike D6D, where no signal could be seen in AT (Table 2). No locus was significantly associated with CE-SCD (Figure S3) but one variant close to $S C D$, in polycystic kidney disease 2-like 1 (PKD2L1), was significantly associated with AT-SCD, which was analyzed in ULSAM (Table 2). The same direction of effect was seen for CE-SCD, though the association was weaker $\left(\mathrm{P}=1.6 \times 10^{-4}\right)$.

By conditional association tests of the FADS1-FADS2-FADS3 region, in a forward selection approach, two SNPs (rs174549, rs968567) were independently associated with CE-D5D and two SNPs (rs138194593, rs2072113) were independently associated with CE-D6D (Table S2). The four SNPs were not in strong LD $(\mathrm{R} 2 \leq 0.40)$ with each other.

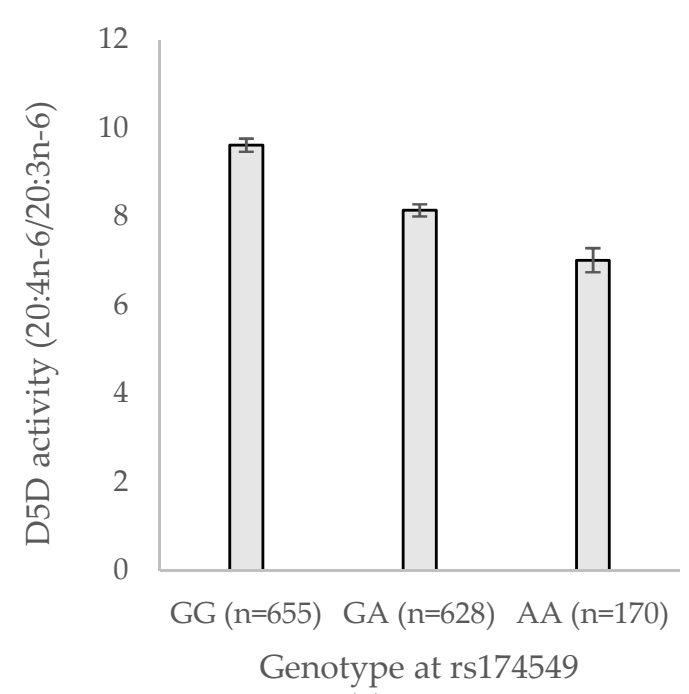

(a)

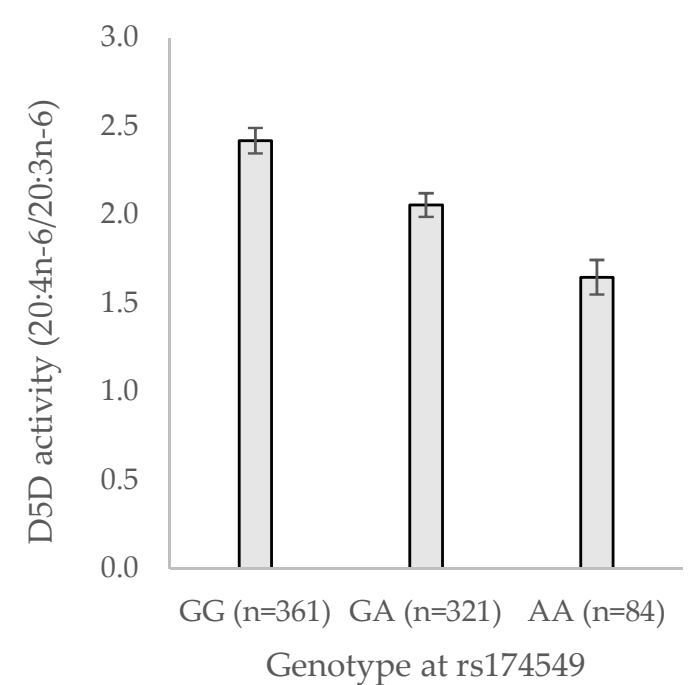

(b)

Figure 1. Estimated $\delta$-5-desaturase (D5D) activity in cholesterol esters (a) and adipose tissue (b) by genotype at rs174549. Values are means and error bars represent $95 \%$ confidence intervals of means. D5D activity was estimated as the ratio of arachidonic acid $(20: 4 n-6)$ and dihomo-gamma-linolenic acid (20:3n-6).

\subsection{SNP Lookup}

Database searches revealed that the variants independently associated with D5D activity are located in transcription factor binding regions (cited in RegulomeDB [15]) and have been associated with expression of FADS1 and FADS2 in diverse tissues (cited in GTEx [16]). In previous GWAS, the two SNPs independently associated with D5D (or variants in full LD) have been linked to circulating polyunsaturated fatty acids [6,19-22]. In studies utilizing candidate SNP approaches, the same SNPs have been associated with FA and ratios thereof in circulation and tissue [23-27].

The lead variant associated with estimated D6D activity, rs138194593, is located in an intronic region of the FADS2 gene and has been associated with FADS2 expression in blood from Estonian coronary artery disease patients [28]. The second independent D6D-associated SNP in the FADS2 gene, rs2072113, or proxies in full LD have been associated to FADS expression (as cited in GTEx [16]) and been linked to circulating PUFA in previous GWAS $[5,6,19,21]$. Another variant linked with D6D activity, rs6498540, is located in PDXDC1 and has been associated with circulating PUFA and FA ratios $[6,21]$. 
Table 2. Common variants (MAF $\geq 5 \%$ ) with $p<1 \times 10^{-8}$. a

\begin{tabular}{|c|c|c|c|c|c|c|c|c|c|c|c|}
\hline \multirow{2}{*}{ Desaturase } & \multirow{2}{*}{ Gene } & \multirow{2}{*}{ Lead SNP } & \multirow{2}{*}{ Chr:Position (b37) } & \multirow{2}{*}{ EAF } & \multirow{2}{*}{$\begin{array}{l}\text { Effect Allele/ } \\
\text { Other Allele }\end{array}$} & \multicolumn{3}{|c|}{ Serum } & \multicolumn{3}{|c|}{ Adipose Tissue } \\
\hline & & & & & & Direction & $p$ & $n$ & Direction & $p$ & $n$ \\
\hline D5D & FADS1 & rs174549 & 11:61571382 & 0.33 & $\mathrm{~A} / \mathrm{G}$ & - & $1.9 \times 10^{-70}$ & 1448 & - & $1.1 \times 10^{-27}$ & 766 \\
\hline D6D & FADS2 & rs138194593 & 11:61620703 & 0.63 & СТСТT/C & + & $3.0 \times 10^{-67}$ & 1448 & - & $7.9 \times 10^{-1}$ & 611 \\
\hline D6D & PDXDC1 & rs6498540 & $16: 15130594$ & 0.71 & $\mathrm{~A} / \mathrm{G}$ & + & $4.8 \times 10^{-8}$ & 1448 & - & $2.9 \times 10^{-1}$ & 611 \\
\hline D6D & near $M C 4 R$ & rs9957425 & 18:57462103 & 0.61 & $\mathrm{~T} / \mathrm{C}$ & + & $3.7 \times 10^{-8}$ & 1448 & - & $9.0 \times 10^{-1}$ & 611 \\
\hline SCD & PKD2L1 & rs603424 & 10:102075479 & 0.14 & $\mathrm{~A} / \mathrm{G}$ & - & $1.6 \times 10^{-4}$ & 1453 & - & $2.2 \times 10^{-19}$ & 783 \\
\hline
\end{tabular}

a A, adenine; C, cytosine; Chr, chromosome; b37, NCBI build 37; D5D, 8 -5-desaturase; D6D, $\delta$-6-desaturase; EAF, effect allele frequency; FADS1, fatty acid desaturase 1; FADS2, fatty acid desaturase 2; G, guanine; $M C 4 R$, melanocortin 4 receptor; $P D X D C 1$, pyridoxal-dependent decarboxylase domain containing 1 ; $P K D 2 L 1$, polycystic kidney disease 2-like 1; SCD, Stearoyl-CoA desaturase; T, thymine. 
In addition, rs6498540 is in perfect LD with rs4500751, a SNP in a transcription binding region (as cited in RegulomeDB [15]) close to PDXDC1 and NTAN1 that has been associated with circulating PUFA and ratios thereof in previous GWAS $[5,6,29]$. This SNP is also located $300 \mathrm{~kb}$ from PLAG10, a gene involved in phospholipid metabolism, possibly with a fatty-acid specific mechanism [29]. The top SNP of the third locus associated with D6D activity, rs9957425, is not in strong LD with other SNPs $\left(r^{2}<0.32\right)$ and is not likely in a transcript factor binding region but may affect epigenetic modifications (as cited in RegulomeDB [15]). It has not yet been associated with circulating FA or FA ratios and has not been strongly associated $(p \geq 0.02)$ with any traits in the GWAS included in the Metabolomic GWAS scanner [5,6] or PhenoScanner [17]. The variant is located $576 \mathrm{~kb}$ downstream of $M C 4 R$, in close proximity to a region strongly associated with diabetes and related traits.

The variant associated with AT-SCD, rs603424 in the PKLD1 gene, is located $31 \mathrm{~kb}$ from the SCD gene [29] and has previously been associated with adipose SCD expression and circulating saturated fatty acids, monounsaturated fatty acids and ratios thereof $[5,29,30]$.

\subsection{Associations of Identified Loci with Metabolic Traits}

After correcting for multiple testing, the lead SNP at one of the loci significantly associated with estimated D6D activity, rs9957425, was associated with BMI $\left(p=7.4 \times 10^{-4}\right)$ and plasma triglycerides $\left(p=2.1 \times 10^{-3}\right)$ in a meta-analysis of ULSAM and PIVUS data (Table 3). The same locus was also associated to M-value in ULSAM $\left(p=3.8 \times 10^{-3}\right)$. Associations of the other loci with BMI, HOMA-IR, M-value plasma HDL, triglycerides, or M-value were not evident after correcting for multiple testing (Table 3). All significant loci from the single variant analysis, except rs603424 (PKD2L1, close to SCD), were associated with HDL cholesterol or triglycerides $(p<0.05)$ in a large meta-analysis of lipid values (Table S3) [31]. In additional lookups of published data, no significant associations were seen for HOMA-IR [4] and only rs6498540 showed some evidence of association for BMI [32]. 
Table 3. Associations of significant desaturase loci with BMI and metabolic traits. ${ }^{\text {a }}$

\begin{tabular}{|c|c|c|c|c|c|c|c|c|c|c|c|c|c|c|}
\hline \multirow{3}{*}{ Gene } & \multirow{3}{*}{ rs ID ${ }^{b}$} & \multirow{3}{*}{$\begin{array}{l}\text { Chr:Position } \\
\quad \text { (b37) }\end{array}$} & \multirow{3}{*}{$\begin{array}{l}\text { Effect } \\
\text { Allele }\end{array}$} & \multirow{3}{*}{ EAF } & \multicolumn{8}{|c|}{ ULSAM + PIVUS Meta-Analysis $(n=1453)$} & \multirow{2}{*}{\multicolumn{2}{|c|}{$\begin{array}{c}\text { ULSAM }(n=564) \\
\text { M-Value }\end{array}$}} \\
\hline & & & & & \multicolumn{2}{|c|}{ HDL Cholesterol } & \multicolumn{2}{|c|}{ Triglycerides } & \multicolumn{2}{|c|}{ BMI } & \multicolumn{2}{|c|}{ HOMA-IR } & & \\
\hline & & & & & Direction & $p$ & Direction & $p$ & Direction & $p$ & Direction & $p$ & Direction & $p$ \\
\hline FADS1 & rs174549 & $11: 61571382$ & A & 0.33 & - & $2.0 \times 10^{-2}$ & + & $1.8 \times 10^{-1}$ & + & $5.4 \times 10^{-1}$ & + & $6.9 \times 10^{-1}$ & - & $7.6 \times 10^{-1}$ \\
\hline FADS2 & rs968567 & $11: 61595564$ & $\mathrm{~T}$ & 0.15 & - & $2.4 \times 10^{-1}$ & + & $5.5 \times 10^{-1}$ & + & $1.1 \times 10^{-1}$ & + & $5.6 \times 10^{-2}$ & - & $2.1 \times 10^{-1}$ \\
\hline FADS2 & rs138194593 & 11:61620703 & CTCTT & 0.63 & + & $9.3 \times 10^{-3}$ & - & $4.2 \times 10^{-1}$ & - & $1.8 \times 10^{-1}$ & - & $7.9 \times 10^{-1}$ & + & $5.3 \times 10^{-1}$ \\
\hline FADS2 & rs2072113 & 11:61604967 & $\mathrm{T}$ & 0.17 & - & $7.6 \times 10^{-2}$ & + & $3.9 \times 10^{-1}$ & - & $7.3 \times 10^{-1}$ & - & $2.5 \times 10^{-1}$ & + & $5.8 \times 10^{-1}$ \\
\hline PDXDC1 & rs6498540 & 16:15130594 & A & 0.71 & + & $7.8 \times 10^{-1}$ & - & $8.5 \times 10^{-1}$ & - & $4.2 \times 10^{-1}$ & + & $3.7 \times 10^{-1}$ & + & $7.6 \times 10^{-1}$ \\
\hline near $M C 4 R$ & rs 9957425 & $18: 57462103$ & $\mathrm{~T}$ & 0.61 & - & $2.2 \times 10^{-1}$ & $++^{c}$ & $2.1 \times 10^{-3}$ & $+^{\mathrm{c}}$ & $7.4 \times 10^{-4}$ & + & $7.1 \times 10^{-2}$ & $-{ }^{c}$ & $3.8 \times 10^{-3}$ \\
\hline PKD2L1 & rs603424 & 10:102075479 & A & 0.14 & + & $8.4 \times 10^{-1}$ & + & $5.2 \times 10^{-1}$ & + & $8.8 \times 10^{-1}$ & + & $8.8 \times 10^{-1}$ & - & $7.6 \times 10^{-2}$ \\
\hline
\end{tabular}

${ }^{a}$ Chr, chromosome; b37, NCBI build 37; EAF, effect allele frequency; FADS1, fatty acid desaturase 1; FADS2, fatty acid desaturase 2; PDXDC1, pyridoxal-dependent decarboxylase domain containing 1; MC4R, melanocortin 4 receptor; PKD2L1, polycystic kidney disease 2-like 1; PIVUS, Prospective Investigation of Uppsala Seniors; ULSAM, Uppsala Longitudinal Study of Adult Men; HDL, high-density lipoprotein; BMI, body mass index; HOMA-IR, homeostasis model assessment of insulin resistance. ${ }^{\mathrm{b}}$ Reference SNP ID number. ${ }^{\mathrm{c}}$ Significant association after adjustment for multiple testing. 


\section{Discussion}

In the present study, five loci were associated at a genome-wide significant level with estimated activities of D5D, D6D, or SCD in the two population-based Swedish cohort studies ULSAM and PIVUS. One of these loci, downstream of MC4R, was additionally associated to BMI and triglycerides in the combined study populations; and to M-value in ULSAM, after correcting for multiple testing.

Most variants identified in the present study or proxies in perfect LD have been associated with circulating FAs, ratios thereof or FADS gene expression in previous GWAS [5,6,19-22,28-30]. However, one novel variant near the $M C 4 R$ gene was identified. Polymorphisms downstream of the $M C 4 R$ gene are among the strongest genetic determinants of BMI and they have been associated with food preference, IS and HDL [33]. Estimated D6D activity has likewise previously been positively associated to obesity $[34,35]$ and it can be speculated that the observed associations of rs 9957425 with desaturase activity, BMI and IS are due to MC4R-mediated effects on food and fatty acid intake, which could influence FA proportions and thereby the FA ratio used for estimating D6D activity.

As expected, the strongest associations with estimated D5D and D6D activities in ULSAM and PIVUS were observed with variants mapped to the FADS cluster, which supports the use of FA ratios as estimates of desaturase activity. Polymorphism in FADS encoding genes may be directly linked to IS and T2D [36]; however, identification of such associations could be hampered by high LD in the FADS region and pleiotropy of the FADS genes. Most genetic variants associated with FADS activity were linked to blood lipid levels in meta-analysis of published GWAS [31], supporting the relationships between FADS activity and development of metabolic syndrome [37]. Thus, it is a challenge to disentangle the potential direct role of FADS gene variants on IS, from that of closely related metabolic disorders such as triglycerides and HDL.

The correlations between the estimated enzyme activities in CE and AT observed in the present study confirm results from a previous study in which activities of D5D and SCD in AT and serum were correlated in Swedish men and women [35]. In that study, D6D activity estimated in AT was correlated with that estimated in phospholipids but not non-esterified serum FA. Another study reported that estimated enzyme activities of D5D, D6D and SCD in serum (calculated from total FA in serum) were highly correlated with corresponding activities in liver tissue but not in AT [38]. Similarly, enzyme activities of fatty acid desaturases estimated in different plasma lipid fractions are not ubiquitously correlated, though enzyme activities estimated in cholesteryl esters used in the present study are considered to reflect hepatic fatty acid desaturation [35,39].

Associations between gene expression and enzyme activity of SCD have been observed in liver [40], AT [41] and brain [42]. It should be noted that SCD gene expression may differ in different adipose tissue depots and we have reported that SCD gene expression was correlated with estimated SCD activity in subcutaneous but not in visceral adipose tissue [43].

Similar associations for D5D have been observed in brain [42] and for D6D in liver [40]. Although product-to-substrate ratios are indirect measurements of enzyme activity and their accuracy has been questioned [44,45], FA ratios correlate with direct enzyme activity measurements (by isotope tracer) [46]. The FA composition of CE is regulated in the liver and plasma, while the composition in AT is influenced by adipose metabolism [47]. For example, FA are released from AT by lipase-catalyzed lipolysis and diverse mobilization of individual FA from AT that could affect the ability of FA ratios to estimate enzyme activity in AT [48]. Hence, as FA ratios in CE and AT represent desaturase activities in various tissues (i.e., liver, plasma and adipocytes) they may be affected by diverse genetic determinants.

A major strength of the present study is the availability of data on FADS activity estimated in both AT and serum and to our knowledge this is the first GWAS of adipose FADS activity. Furthermore, IS was assessed both by the gold standard methodology hyperinsulinemic euglycemic clamp and calculated using HOMA-IR. The combination of the two cohorts, ULSAM and PIVUS resulted in dataset consisting of men and women with measured FA composition.

The relatively small sample size of the two cohorts utilized is a limitation of the present study. Also, data on adipose FADS activity and M-value were only available in one of the cohorts, ULSAM. 
As the two cohorts consist of individuals from the same geographical location, there is a possibility that the two study population are too homogeneous and thus the possibility to identify associations between genes and fatty acid metabolism are hampered by low genetic variation. Further, the generalizability to other ethnicities is unknown.

Our findings have implications for future research. First, our findings support the use of FA ratios as indirect estimates of desaturase activity, given that the variants most strongly associated with FA ratios were located in or near desaturase encoding genes. However, certain lipid fractions may be less suitable to assess desaturase activity by FA ratios as suggested by the inconsistency in loci associated with D6D and SCD in different fractions. In addition, our findings warrant further evaluation of rs9957425, associated with both desaturase activity and cardiometabolic traits.

\section{Conclusions}

In conclusion, the activities of FADS estimated in CE and AT were associated with variants in or near five independent loci (FADS1, FADS2, MC4R, PDKL1 and PDXDC1). One of the loci (FADS1) was associated with FADS activity in both CE and AT. One variant associated with estimated D6D activity (rs9957425 near MC4R) was additionally was associated to BMI, TG and intravenously assessed IS. Activities of D5D and SCD estimated in CE and AT were correlated, while no correlation was observed for D6D activity estimated in the different tissues.

Supplementary Materials: The following are available online at http:/ / www.mdpi.com/2072-6643/10/11/1791/ s1; Figure S1: Manhattan plot of the meta-analysis of the single-variant association results of serum D5D; Figure S2: Manhattan plot of the meta-analysis of the single-variant association results of serum D6D; Figure S3: Manhattan plot of the meta-analysis of the single-variant association results of serum SCD; Table S1: Sample exclusion criteria and number of samples excluded after quality control in ULSAM and PIVUS; Table S2: Secondary signals significant at $p$-value $\sim 10-5$ after adjustment for the lead variant; Table S3: Results for the significant loci in the single variant analysis extracted from published meta-analyses of GWAS for HOMA-IR, HDL cholesterol, triglycerides and BMI.

Author Contributions: Conceptualization, M.M., E.I. and U.R.; formal analysis, A.M.; investigation, M.M. and A.M.; resources, L.L. and U.R.; writing—original draft preparation, M.M.; writing—review and editing, M.M., A.P.M., A.M., E.I., C.M.L., L.L. and U.R.; visualization, M.M.; supervision, U.R.; funding acquisition, M.M., U.R. and C.M.L.

Funding: This work was funded by the Swedish Research Council, grant number 2007-2135; Swedish Heart-Lung Foundation, grant number 20070212; Swedish Research Council for Health, Working Life and Welfare; grant number 2013-01586; Royal Swedish Academy of Science, the Swedish Foundation for Strategic Research; the Swedish Diabetes Foundation; the Swedish Society of Medicine; the Novo Nordisk Foundation; Karolinska Foundation; AstraZeneca R\&D Mölndal; the Northern Sweden Councils (Visare Norr); the European Community's Seventh Framework Programme, grant number FP7/2007-2013; ENGAGE Consortium, grant agreement HEALTH-F4-2007-201413; C.M.L. is supported by the Li Ka Shing Foundation, WT-SSI/John Fell funds and by the NIHR Biomedical Research Centre, Oxford, by Widenlife and NIH (5P50HD028138-27). The computations were performed on resources provided by SNIC through Uppsala Multidisciplinary Center for Advanced Computational Science (UPPMAX) under Project p2013055.

Acknowledgments: We thank Mohammed Bajahzer for assistance in graphical presentation and we acknowledge the participants of PIVUS and ULSAM.

Conflicts of Interest: The authors declare no conflict of interest. The funders had no role in the design of the study; in the collection, analyses, or interpretation of data; in the writing of the manuscript, or in the decision to publish the results.

\section{References}

1. Warensjö, E.; Risérus, U.; Gustafsson, I.-B.; Mohsen, R.; Cederholm, T.; Vessby, B. Effects of saturated and unsaturated fatty acids on estimated desaturase activities during a controlled dietary intervention. Nutr. Metab. Cardiovasc. Dis. 2008, 18, 683-690. [CrossRef] [PubMed]

2. Vessby, B.; Gustafsson, I.B.; Tengblad, S.; Boberg, M.; Andersson, A. Desaturation and elongation of Fatty acids and insulin action. Ann. N. Y. Acad. Sci. 2002, 967, 183-195. [CrossRef] [PubMed]

3. Kroger, J.; Schulze, M.B. Recent insights into the relation of Delta5 desaturase and Delta6 desaturase activity to the development of type 2 diabetes. Curr. Opin. Lipidol. 2012, 23, 4-10. [CrossRef] [PubMed] 
4. Dupuis, J.; Langenberg, C.; Prokopenko, I.; Saxena, R.; Soranzo, N.; Jackson, A.U.; Wheeler, E.; Glazer, N.L.; Bouatia-Naji, N.; Gloyn, A.L.; et al. New genetic loci implicated in fasting glucose homeostasis and their impact on type 2 diabetes risk. Nat. Genet. 2010, 42, 105-116. [CrossRef] [PubMed]

5. Suhre, K.; Shin, S.Y.; Petersen, A.K.; Mohney, R.P.; Meredith, D.; Wagele, B.; Altmaier, E.; Deloukas, P.; Erdmann, J.; Grundberg, E.; et al. Human metabolic individuality in biomedical and pharmaceutical research. Nature 2011, 477, 54-60. [CrossRef] [PubMed]

6. Shin, S.Y.; Fauman, E.B.; Petersen, A.K.; Krumsiek, J.; Santos, R.; Huang, J.; Arnold, M.; Erte, I.; Forgetta, V.; Yang, T.P.; et al. An atlas of genetic influences on human blood metabolites. Nat. Genet. 2014, 46, 543-550. [CrossRef] [PubMed]

7. Hedstrand, H. A study of middle-aged men with particular reference to risk factors for cardiovascular disease. Upsala J. Med. Sci. Suppl. 1975, 19, 1-61.

8. Lind, L.; Fors, N.; Hall, J.; Marttala, K.; Stenborg, A. A comparison of three different methods to evaluate endothelium-dependent vasodilation in the elderly: The Prospective Investigation of the Vasculature in Uppsala Seniors (PIVUS) study. Arterioscler. Thromb. Vasc. Biol. 2005, 25, 2368-2375. [CrossRef] [PubMed]

9. Rosqvist, F.; Bjermo, H.; Kullberg, J.; Johansson, L.; Michaëlsson, K.; Ahlström, H.; Lind, L.; Risérus, U. Fatty acid composition in serum cholesterol esters and phospholipids is linked to visceral and subcutaneous adipose tissue content in elderly individuals: A cross-sectional study. Lipids Health Dis. 2017, 16, 68. [CrossRef] [PubMed]

10. Iggman, D.; Arnlov, J.; Cederholm, T.; Riserus, U. Association of Adipose Tissue Fatty Acids with Cardiovascular and All-Cause Mortality in Elderly Men. JAMA Cardiol. 2016, 1, 745-753. [CrossRef] [PubMed]

11. Nerpin, E.; Riserus, U.; Ingelsson, E.; Sundstrom, J.; Jobs, M.; Larsson, A.; Basu, S.; Arnlov, J. Insulin sensitivity measured with euglycemic clamp is independently associated with glomerular filtration rate in a community-based cohort. Diabetes Care 2008, 31, 1550-1555. [CrossRef] [PubMed]

12. Purcell, S.; Neale, B.; Todd-Brown, K.; Thomas, L.; Ferreira, M.A.; Bender, D.; Maller, J.; Sklar, P.; de Bakker, P.I.; Daly, M.J.; et al. PLINK: A tool set for whole-genome association and population-based linkage analyses. Am. J. Hum. Genet. 2007, 81, 559-575. [CrossRef] [PubMed]

13. Willer, C.J.; Li, Y.; Abecasis, G.R. METAL: Fast and efficient meta-analysis of genomewide association scans. Bioinformatics 2010, 26, 2190-2191. [CrossRef] [PubMed]

14. Marchini, J.; Howie, B. Genotype imputation for genome-wide association studies. Nat. Rev. Genet. 2010, 11, 499-511. [CrossRef] [PubMed]

15. Boyle, A.P.; Hong, E.L.; Hariharan, M.; Cheng, Y.; Schaub, M.A.; Kasowski, M.; Karczewski, K.J.; Park, J.; Hitz, B.C.; Weng, S.; et al. Annotation of functional variation in personal genomes using RegulomeDB. Genome Res. 2012, 22, 1790-1797. [CrossRef] [PubMed]

16. The Genotype-Tissue Expression (GTEx) project. Nat. Genet. 2013, 45, 580-585. [CrossRef] [PubMed]

17. Staley, J.R.; Blackshaw, J.; Kamat, M.A.; Ellis, S.; Surendran, P.; Sun, B.B.; Paul, D.S.; Freitag, D.; Burgess, S.; Danesh, J.; et al. PhenoScanner: A database of human genotype-phenotype associations. Bioinformatics 2016, 32, 3207-3209. [CrossRef] [PubMed]

18. Benjamini, Y.; Hochberg, Y. Controlling the false discovery rate: A practical and powerful approach to multiple testing. J. R. Stat. Soc. Ser. B Methodol. 1995, 57, 289-300.

19. Lemaitre, R.N.; Tanaka, T.; Tang, W.; Manichaikul, A.; Foy, M.; Kabagambe, E.K.; Nettleton, J.A.; King, I.B.; Weng, L.C.; Bhattacharya, S.; et al. Genetic loci associated with plasma phospholipid n-3 fatty acids: A meta-analysis of genome-wide association studies from the CHARGE Consortium. PLoS Genet. 2011, 7, e1002193. [CrossRef] [PubMed]

20. Voruganti, V.S.; Higgins, P.B.; Ebbesson, S.O.; kennish, J.; Goring, H.H.; Haack, K.; Laston, S.; Drigalenko, E.; Wenger, C.R.; Harris, W.; et al. Variants in CPT1A, FADS1, and FADS2 are associated with higher levels of estimated plasma and erythrocyte delta 5 desaturases in Alaskan Eskimos. Front. Genet. 2012, 3. [CrossRef] [PubMed]

21. Kettunen, J.; Tukiainen, T.; Sarin, A.P.; Ortega-Alonso, A.; Tikkanen, E.; Lyytikainen, L.P.; Kangas, A.J.; Soininen, P.; Wurtz, P.; Silander, K.; et al. Genome-wide association study identifies multiple loci influencing human serum metabolite levels. Nat. Genet. 2012, 44, 269-276. [CrossRef] [PubMed] 
22. Guan, W.; Steffen, B.T.; Lemaitre, R.N.; Wu, J.H.; Tanaka, T.; Manichaikul, A.; Foy, M.; Rich, S.S.; Wang, L.; Nettleton, J.A.; et al. Genome-wide association study of plasma N6 polyunsaturated fatty acids within the cohorts for heart and aging research in genomic epidemiology consortium. Circ. Cardiovasc. Genet. 2014, 7, 321-331. [CrossRef] [PubMed]

23. Bokor, S.; Dumont, J.; Spinneker, A.; Gonzalez-Gross, M.; Nova, E.; Widhalm, K.; Moschonis, G.; Stehle, P.; Amouyel, P.; De Henauw, S.; et al. Single nucleotide polymorphisms in the FADS gene cluster are associated with delta- 5 and delta- 6 desaturase activities estimated by serum fatty acid ratios. J. Lipid Res. 2010, 51, 2325-2333. [CrossRef] [PubMed]

24. Koletzko, B.; Lattka, E.; Zeilinger, S.; Illig, T.; Steer, C. Genetic variants of the fatty acid desaturase gene cluster predict amounts of red blood cell docosahexaenoic and other polyunsaturated fatty acids in pregnant women: Findings from the Avon Longitudinal Study of Parents and Children. Am. J. Clin. Nutr. 2011, 93, 211-219. [CrossRef] [PubMed]

25. Merino, D.M.; Johnston, H.; Clarke, S.; Roke, K.; Nielsen, D.; Badawi, A.; El-Sohemy, A.; Ma, D.W.; Mutch, D.M. Polymorphisms in FADS1 and FADS2 alter desaturase activity in young Caucasian and Asian adults. Mol. Genet. Metab. 2011, 103, 171-178. [CrossRef] [PubMed]

26. Aslibekyan, S.; Jensen, M.K.; Campos, H.; Linkletter, C.D.; Loucks, E.B.; Ordovas, J.M.; Deka, R.; Rimm, E.B.; Baylin, A. Fatty Acid desaturase gene variants, cardiovascular risk factors, and myocardial infarction in the costa rica study. Front. Genet. 2012, 3, 72. [CrossRef] [PubMed]

27. Freemantle, E.; Lalovic, A.; Mechawar, N.; Turecki, G. Age and Haplotype Variations within FADS1 Interact and Associate with Alterations in Fatty Acid Composition in Human Male Cortical Brain Tissue. PLoS ONE 2012, 7. [CrossRef] [PubMed]

28. Franzén, O.; Ermel, R.; Cohain, A.; Akers, N.K.; Di Narzo, A.; Talukdar, H.A.; Foroughi-Asl, H.; Giambartolomei, C.; Fullard, J.F.; Sukhavasi, K.; et al. Cardiometabolic risk loci share downstream cisand trans-gene regulation across tissues and diseases. Science 2016, 353, 827-830. [CrossRef] [PubMed]

29. Demirkan, A.; van Duijn, C.M.; Ugocsai, P.; Isaacs, A.; Pramstaller, P.P.; Liebisch, G.; Wilson, J.F.; Johansson, A.; Rudan, I.; Aulchenko, Y.S.; et al. Genome-wide association study identifies novel loci associated with circulating phospho- and sphingolipid concentrations. PLoS Genet. 2012, 8, e1002490. [CrossRef] [PubMed]

30. Wu, J.H.; Lemaitre, R.N.; Manichaikul, A.; Guan, W.; Tanaka, T.; Foy, M.; Kabagambe, E.K.; Djousse, L.; Siscovick, D.; Fretts, A.M.; et al. Genome-wide association study identifies novel loci associated with concentrations of four plasma phospholipid fatty acids in the de novo lipogenesis pathway: Results from the Cohorts for Heart and Aging Research in Genomic Epidemiology (CHARGE) consortium. Circ. Cardiovasc. Genet. 2013, 6, 171-183. [CrossRef] [PubMed]

31. Willer, C.J.; Schmidt, E.M.; Sengupta, S.; Peloso, G.M.; Gustafsson, S.; Kanoni, S.; Ganna, A.; Chen, J.; Buchkovich, M.L.; Mora, S.; et al. Discovery and refinement of loci associated with lipid levels. Nat. Genet. 2013, 45, 1274-1283. [CrossRef] [PubMed]

32. Locke, A.E.; Kahali, B.; Berndt, S.I.; Justice, A.E.; Pers, T.H.; Day, F.R.; Powell, C.; Vedantam, S.; Buchkovich, M.L.; Yang, J.; et al. Genetic studies of body mass index yield new insights for obesity biology. Nature 2015, 518, 197-206. [CrossRef] [PubMed]

33. Loos, R.J.; Lindgren, C.M.; Li, S.; Wheeler, E.; Zhao, J.H.; Prokopenko, I.; Inouye, M.; Freathy, R.M.; Attwood, A.P.; Beckmann, J.S.; et al. Common variants near MC4R are associated with fat mass, weight and risk of obesity. Nat. Genet. 2008, 40, 768-775. [CrossRef] [PubMed]

34. Warensjo, E.; Ohrvall, M.; Vessby, B. Fatty acid composition and estimated desaturase activities are associated with obesity and lifestyle variables in men and women. Nutr. Metab. Cardiovasc. Dis. 2006, 16, 128-136. [CrossRef] [PubMed]

35. Warensjo, E.; Rosell, M.; Hellenius, M.L.; Vessby, B.; De Faire, U.; Riserus, U. Associations between estimated fatty acid desaturase activities in serum lipids and adipose tissue in humans: Links to obesity and insulin resistance. Lipids Health Dis. 2009, 8, 37. [CrossRef] [PubMed]

36. Kroger, J.; Zietemann, V.; Enzenbach, C.; Weikert, C.; Jansen, E.H.; Doring, F.; Joost, H.G.; Boeing, H.; Schulze, M.B. Erythrocyte membrane phospholipid fatty acids, desaturase activity, and dietary fatty acids in relation to risk of type 2 diabetes in the European Prospective Investigation into Cancer and Nutrition (EPIC)-Potsdam Study. Am. J. Clin. Nutr. 2011, 93, 127-142. [CrossRef] [PubMed] 
37. Warensjo, E.; Riserus, U.; Vessby, B. Fatty acid composition of serum lipids predicts the development of the metabolic syndrome in men. Diabetologia 2005, 48, 1999-2005. [CrossRef] [PubMed]

38. Kotronen, A.; Seppanen-Laakso, T.; Westerbacka, J.; Kiviluoto, T.; Arola, J.; Ruskeepaa, A.L.; Yki-Jarvinen, H.; Oresic, M. Comparison of lipid and fatty acid composition of the liver, subcutaneous and intra-abdominal adipose tissue, and serum. Obesity (Silver Spring) 2010, 18, 937-944. [CrossRef] [PubMed]

39. Gray, R.G.; Kousta, E.; McCarthy, M.I.; Godsland, I.F.; Venkatesan, S.; Anyaoku, V.; Johnston, D.G. Ethnic variation in the activity of lipid desaturases and their relationships with cardiovascular risk factors in control women and an at-risk group with previous gestational diabetes mellitus: A cross-sectional study. Lipids Health Dis. 2013, 12. [CrossRef] [PubMed]

40. Peter, A.; Cegan, A.; Wagner, S.; Lehmann, R.; Stefan, N.; Konigsrainer, A.; Konigsrainer, I.; Haring, H.U.; Schleicher, E. Hepatic lipid composition and stearoyl-coenzyme A desaturase 1 mRNA expression can be estimated from plasma VLDL fatty acid ratios. Clin. Chem. 2009, 55, 2113-2120. [CrossRef] [PubMed]

41. Sjogren, P.; Sierra-Johnson, J.; Gertow, K.; Rosell, M.; Vessby, B.; de Faire, U.; Hamsten, A.; Hellenius, M.L.; Fisher, R.M. Fatty acid desaturases in human adipose tissue: Relationships between gene expression, desaturation indexes and insulin resistance. Diabetologia 2008, 51, 328-335. [CrossRef] [PubMed]

42. McNamara, R.K.; Liu, Y.; Jandacek, R.; Rider, T.; Tso, P. The aging human orbitofrontal cortex: Decreasing polyunsaturated fatty acid composition and associated increases in lipogenic gene expression and stearoyl-CoA desaturase activity. Prostaglandins Leukot. Essent. Fatty Acids 2008, 78, 293-304. [CrossRef] [PubMed]

43. Petrus, P.; Edholm, D.; Rosqvist, F.; Dahlman, I.; Sundbom, M.; Arner, P.; Ryden, M.; Riserus, U. Depot-specific differences in fatty acid composition and distinct associations with lipogenic gene expression in abdominal adipose tissue of obese women. Int. J. Obes. (Lond.) 2017, 41, 1295-1298. [CrossRef] [PubMed]

44. Poisson, J.P.G.; Cunnane, S.C. Long-Chain Fatty-Acid Metabolism in Fasting And Diabetes-Relation between Altered Desaturase Activity and Fatty-Acid Composition. J. Nutr. Biochem. 1991, 2, 60-70. [CrossRef]

45. Brown, J.E. A critical review of methods used to estimate linoleic acid Delta 6-desaturation ex vivo and in vivo. Eur. J. Lipid Sci. Technol. 2005, 107, 119-134. [CrossRef]

46. Gillingham, L.G.; Harding, S.V.; Rideout, T.C.; Yurkova, N.; Cunnane, S.C.; Eck, P.K.; Jones, P.J. Dietary oils and FADS1-FADS2 genetic variants modulate [13C]alpha-linolenic acid metabolism and plasma fatty acid composition. Am. J. Clin. Nutr. 2013, 97, 195-207. [CrossRef] [PubMed]

47. Hodson, L.; Skeaff, C.M.; Fielding, B.A. Fatty acid composition of adipose tissue and blood in humans and its use as a biomarker of dietary intake. Prog. Lipid Res. 2008, 47, 348-380. [CrossRef] [PubMed]

48. Connor, W.E.; Lin, D.S.; Colvis, C. Differential mobilization of fatty acids from adipose tissue. J. Lipid Res. 1996, 37, 290-298.

(C) 2018 by the authors. Licensee MDPI, Basel, Switzerland. This article is an open access article distributed under the terms and conditions of the Creative Commons Attribution (CC BY) license (http:/ / creativecommons.org/licenses/by/4.0/). 